\title{
Sistem Informasi E-Ticketing di PT Pos Indonesia Cabang Cianjur berbasis Web dengan Metode Fifo
}

\author{
Teguh Wiharko ${ }^{1}$, Heru Setiawan ${ }^{2}$ \\ Program Studi Teknik Informatika \\ Fakultas Teknik Universitas Suryakancana \\ teguhwhk@gmail.com ${ }^{1}$,hardzboy7@gmail.com ${ }^{2}$
}

\begin{abstract}
Abstrak
Kantor Pos Indonesia merupakan perusahaan BUMN yang bergerak dalam bidang jasa pelayanan masyarakat yang diperuntukan untuk pengiriman barang, surat, pembayaran multifinance, pembayaran listrik, pembayaran telepon pajak, pengiriman uang, dan pengambilang uang. Setiap transaksi dikelola di bagian loket Pos, sehingga bagian loket sangatlah vital dalam pelayanan kepada masyarakat. Transaksi pembayaran dilakukan dan dikelola oleh beberapa sistem yang berbeda begitupun untuk transaksi lain dilakukan oleh aplikasi yang berbeda-beda. Sistem informasi eticketing pada keluhan PT Pos ini dapat mempermudah pihak IT kantor Pos dalam menyelesaikan masalah - masalah gangguan yang teradi di kantor pos cabang dengan terstruktur dan efisien. Sistem e-ticketing yang akan dibangun dapat membantu pihak KCP agar pengaduan yang lebih mudah dan interaktif, sehingga pihak IT PT Pos akan mengetahui mana saja yang harus diperbaiki dengan menggunakan metode First In, First Out (Pertama Masuk, Pertama Keluar). Dalam membuat sistem informasi e-ticketing ini menggunakan Unified Modelling Language (UML) sebagai bahasa Pemodelannya. Rancangan sistem e-ticketing pada PT Pos ini diimplementasikan berbasis web dimaksudkan agar pihak KCP dapat dengan mudah mengakses dan memperoleh penanggulangan masalah secara cepat. Pembangunan sistem e-ticketing ini dengan menggunakan PHP sebagai bahasa pemrograman, serta MySQL sebagai RDBMS.
\end{abstract}

Kata Kunci : Sistem, E-ticketing, dan UML.

\section{Latar Belakang Masalah}

Perkembangan dalam teknologi informasi saat ini dinilai sangat maju. Beragam kemudahan sudah diaplikasikan oleh teknologi, apalagi teknologi informasi, dimana segala macam informasi sudah bisa diakses dengan mudah dan lengkap untuk berbagai macam kegiatan sehari-hari. Teknologi berkaitan erat dengan sains (science) dan perekayasaan (engineering). Teknologi Informasi adalah salah satu alat yang digunakan oleh para manajer untuk mengatasi perubahan yang terjadi. Dalam hal ini perubahan yang dimaksud adalah perubahan informasi yang telah diolah dan dibuat sebelumnya dalam penyimpanan komputer. (Kenneth C. London, 2004, 6). Perangkat lunak (software) adalah instruksi (program komputer) yang ketika dijalankan menyediakan fungsi dan tampilan yang diinginkan, struktur data yang memberi kesempatan program untuk memanipulasi informasi dan dokumen yang mendeskripsikan operasi dan pengunaan program. (Andi Kristanto). Kantor Pos Indonesia merupakan perusahaan BUMN yang bergerak dalam bidang jasa pelayanan masyarakat yang diperuntukan untuk pengiriman barang, surat, pembayaran multifinance, pembayaran listrik, pembayaran telepon pajak, pengiriman uang, dan pengambilang uang. Setiap transaksi dikelola di bagian loket POS. Tentunya hal tersebut tak lepas dari permasalahan troubleshooting dari sistem yang dijalankan. Permasalahan yang terjadi saat ini ketika terjadi eror pada aplikasi, maka loket atau manager KCP akan menghubungi pihak IT kantor Pos pusat melalui telpon, akan tetapi dalam setiap penanggulangan keluhan sering terjadi keterlambatan penanganan ataupun dilupakan mengingat belum ada system informasi yang dapat secara interaktif dan menyusun segala keluhan secara teratur..

Maka dari itu, dengan adanya sistem informasi $e$ ticketing pada keluhan PT POS ini dapat mempermudah pihak IT kantor Pos dalam menyelesaikan masalah masalah gangguan yang teradi di kantor pos cabang dengan terstruktur dan efisien. Sistem e-ticketing yang akan dibangun dapat membantu pihak KCP agar pengaduan yang lebih mudah dan interaktif, sehingga pihak IT PT Pos akan mengetahui mana saja yang harus diperbaiki dengan menggunakan metode FIFO First In, First Out (Pertama Masuk, Pertama Keluar), sebuah abstraksi yang berhubungan dengan cara mengatur dan memanipulasi data relatif terhadap waktu dan prioritas. Serta dalam pengolahan data gangguan menjadi lebih terstruktur dan terintegrasi sebagai pelaporan ke kepala kantor Pos.

\section{Permasalahan penelitian}

Berdasarkan uraian dari latar belakang permasalahan di atas, maka disusunlah rumusan masalah, yaitu bagaimana membangun sistem e-ticketing untuk pihak KCP agar dapat memudahkan dalam pelaporan pengaduan gangguan pada kinerja aplikasi di kantor Pos loket yang dapat digunakan dengan mudah, efisien dan efektif. 


\section{Maksud dan Tujuan}

Maksud dari penelitian ini adalah membangun sistem e-ticketing untuk pihak KCP agar dapat memudahkan dalam pelaporan pengaduan gangguan pada kinerja aplikasi di kantor POS loket yang dapat digunakan dengan mudah, efisien dan efektif. Adapun Tujuan dari penelitian ini diantaranya adalah :

a. Membantu mengetahui penanganan dalam troubleshooting pada aplikasi di kantor Pos.

b. Memberikan media informasi pengaduan dan gangguan tentang penanganan troubleshooting aplikasi.

c. Membuat perangkat lunak yang dapat digunakan dengan mudah.

d. Memudahkan pihak KCP dalam penanganan troubleshooting aplikasi untuk ditanggulangi oleh pihak IT kantor Pos.

e. Memperingan pekerjaan pihak IT kantor Pos.

f. Mengintegrasikan pelaporan gangguan ke kepala Pos

\section{Landasan Teori}

\subsection{Pengertian Sistem}

Menurut Gordon B. Davis (1992), sistem terdiri dari bagian yang beroprasi untuk mencapai beberapa tujuan, dengan kata lain bahwa suatu sistem bukanlah merupakan suatu perangkat unsur-unsur yang dapar diidentifikasi sebagai kebersamaan yang menyatu disebabkan tujuan atau sasaran yang sama.

Menurut Ludwig Von Bertalanfly (2000), sistem adalah seperangkat unsur-unsur yang terikat dalam suatu antar relasi diantara unsur-unsur tersebut dan dengan lingkungan.

\subsection{Pengertian Informasi}

Menurut Rina Puspita Dewi dkk, informasi adalah data yang telah diproses menjadi bentuk yang memiliki arti bagi yang menerimanya. Informasi merupakan transformasi dari data. Informasi harus mempunyai arti dan nilai nyata untuk dipakai sebagai dasar pengambilan keputusan saat ini atau saat mendatang (2010).

\subsection{Pengertian Sistem Informasi}

Menurut Robert A.Leitch dan K.Roscoe Davis (Jogiyanto, 2005) sistem informasi adalah suatu sistem di dalam suatu organisasi yang mempertemukan kebutuhan pengolahan transaksi harian, mendukung operasi, bersifat manajerial dan kegitan strategi suatu organisasi dan menyediakan pihak luar tertentu dengan laporan-laporan yang diperlukan.

\subsection{Pengertian E-Ticketing}

E-Ticketing atau electronic ticketing adalah suatu cara untuk mendokumentasikan proses penjualan dari aktifitas perjalanan pelanggan tanpa harus mengeluarkan dokumen berharga secara fisik ataupun paper ticket. Semua informasi mengenai electronic ticketing disimpan secara digital dalam sistem komputer milik perusahaan.

\subsection{Pengertian FIFO}

First in First out (FIFO), dimana keluhan yang pertama kali masuk sistem akan dikerjakan pertama kali pula dalam penanganannya, dan siklus keluar masuknya keluhan dapat diketahui dengan jelas.

\section{Analisis Sistem}

\subsection{Analisis Sistem yang Sedang Berjalan}

Proses analisis sistem dalam pengembangan Sistem Informasi merupakan suatu prosedur yang dilakukan untuk pemeriksaan masalah dan penyusunan pemecahan masalah yang timbul serta membuat spesifikasi sistem yang baru. Proses analisis sistem bertujuan untuk mengetahui bagaimana sistem sebelumnya berjalan, agar dalam pengerjaaan sistem yang akan dibuat lebih maksimal karena sudah diketahuinya kelemahan sistem terdahulu. Kantor Pos Indonesia merupakan perusahaan BUMN yang bergerak dalam bidang jasa pelayanan masyarakat yang diperuntukan untuk pengiriman barang, surat, pembayaran multifinance, pembayaran listrik, pembayaran telepon pajak, pengiriman uang, dan pengambilang uang. Setiap transaksi dikelola di bagian loket POS, sehingga bagian loket sangatlah vital dalam pelayanan kepada masyarakat. Transaksi pembayaran dilakukan dan dikelola oleh beberapa sistem yang berbeda, seperti contoh akan melakukan pembayaran pajak dilakukan dalam aplikasi POSPAY, dan untuk melakukan pengiriman barang dan surat dilakukan dalam aplikasi I-POS, begitupun untuk transaksi lain dilakukan oleh aplikasi yang berbeda-beda.

\subsection{Daftar Aktor}

Daftar aktor merupakan orang yang terlibat atau siapa saja yang menggunakan Sistem Informasi E-ticketing Berbasis website ini.

Tabel 1 Aktor pada E-Ticketing

\begin{tabular}{|l|l|}
\hline \multicolumn{1}{|c|}{ Aktor } & \multicolumn{1}{|c|}{ Keterangan } \\
\hline Admin & $\begin{array}{l}\text { Orang yang menerima inputan Ticket dari User } \\
\text { KCP. }\end{array}$ \\
\hline User & $\begin{array}{l}\text { Orang yang menginputkan Ticket terhadap } \\
\text { kantor pusat }\end{array}$ \\
\hline Teknisi & $\begin{array}{l}\text { Orang yang menerima Ticket yang dikirimkan } \\
\text { pusat, dan bertugas memperbaiki Ticket tersebut. }\end{array}$ \\
\hline
\end{tabular}

\subsection{Daftar Use Case}

Daftar use case menjelaskan tentang daftar use case atau function - function yang ada di dalam sistem, daftar use case berisi kode, nama use case, dan keterangan dari tiap masing-masing use case. Berikut use case yang terdapat dalam Sistem Informasi E-ticketing berbasis website.

Tabel 2 Usecase

\begin{tabular}{|l|l|l|}
\hline Kode & Nama Use Case & \multicolumn{1}{|c|}{ Keterangan } \\
\hline U1 & Login & $\begin{array}{l}\text { Function yang digunakan } \\
\text { admin untuk masuk kehalaman } \\
\text { utama Sistem. }\end{array}$ \\
\hline U2 & Halaman Utama & $\begin{array}{l}\text { Halaman ini bisa diakses } \\
\text { apabila User berhasil } \\
\text { melakukan login pada proses } \\
\text { sebelumnya. }\end{array}$ \\
\hline U3 & Input Ticket & Function yang digunakan oleh \\
\hline
\end{tabular}




\begin{tabular}{|c|c|c|}
\hline & & $\begin{array}{llr}\text { User ketika ada } & \text { suatu } \\
\text { permasalahan di KCP. } & \\
\end{array}$ \\
\hline U4 & Daftar Ticket & $\begin{array}{l}\text { Function ini digunakan untuk } \\
\text { mengetahui Data Ticket dari } \\
\text { user setiap KCP }\end{array}$ \\
\hline U5 & $\begin{array}{l}\text { Kirim } \quad \text { Daftar } \\
\text { Ticket }\end{array}$ & $\begin{array}{ll}\text { Function } & \text { ini digunakan oleh } \\
\text { Admin } & \text { Untuk melakukan } \\
\text { proses } & \text { Pengiriman Daftar } \\
\text { Ticket user kepada Teknisi. }\end{array}$ \\
\hline U6 & $\begin{array}{l}\text { Konfirmasi } \\
\text { Konplen }\end{array}$ & $\begin{array}{l}\text { Function ini digunakan untuk } \\
\text { oleh } \\
\text { menkonfirmasi terhadap Ticket } \\
\text { yang di kirimkan oleh admin. }\end{array}$ \\
\hline U7 & Laporan Ticket & $\begin{array}{l}\text { Function ini digunakan untuk } \\
\text { Mengetahui Jumlah Ticket dari } \\
\text { User disetiap KCP. }\end{array}$ \\
\hline U8 & LogOut & $\begin{array}{l}\text { Function ini digunakan ketika } \\
\text { pengguna akan keluar dari } \\
\text { halaman utama }\end{array}$ \\
\hline U9 & Update Progres & $\begin{array}{l}\text { Function ini digunakan ketika } \\
\text { teknisi akan memperbaharui } \\
\text { terhadap pekerjaan yang sudah } \\
\text { dilakukannya. }\end{array}$ \\
\hline U10 & Kelola Pegawai & $\begin{array}{l}\text { Function ini di gunakan untuk } \\
\text { mengelola data pegawai }\end{array}$ \\
\hline U11 & Kelola KCP & $\begin{array}{l}\text { Function ini di gunakan untuk } \\
\text { mengelola data KCP untuk } \\
\text { setiap pegawai }\end{array}$ \\
\hline
\end{tabular}

\subsection{Use Case Diagram}

Use Case merupakan deskripsi fungsi - fungsi di dalam sebuah sistem dari perspektif pengguna. Use case diagram digunakan untuk memperlihatkan fungsionalitas sistem yang akan disediakan dan memperlihatkan pengguna yang berkomunikasi dengan system dengan memanfaatkan setiap fungsi yang ada dalam sistem, Use case adalah abstraksi dari interaksi antara system dan actor Berikut use case diagram dari sistem informasi Eticketing berbasis website.

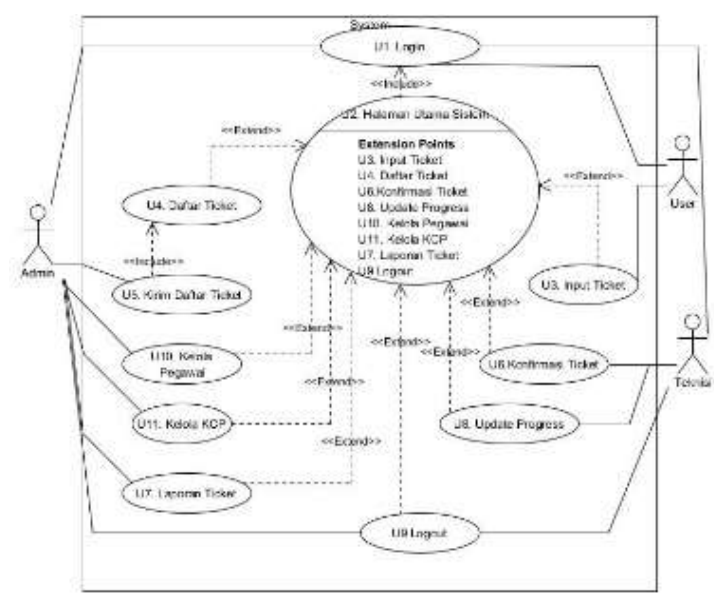

Gambar 1 Use Case Diagram Sistem Informasi Eticketing berbasis website

Pada Gambar Use Case diagram diatas terlihat tiga actor bagaimana dia berinteraksi dengan sistem, actor actor tersebut adalah admin, user dan teknisi, pada use case diagram diatas terdapat tujuh buah use case diamana setiap use case tersebut mempunyai fungsi dan kegunaannya masing-masing dalam sebuah sistem tersebut, akan tetapi semua use case tersebut saling

keterkaitan atau berhubungan dengan use case Ouse case yang lainnya. Pada use case diagram diatas terdapat use case login, use case Input Ticket, use case daftar Ticket, use case kirim daftar Ticket, use case konfirmasi Ticket, dan use case laporan Ticket bulanan. Ketika user dari KCP menginputkan Ticket maka sistem akan mengirimkan Ticket tersebut kepada pusat, admin yang bertugas menerima Ticket dari KCP akan memverifikasi terhadap Ticket yang di inputkan user, kemudian admin akan mengirimkan daftar Ticket tersebut kepada bagian teknisi, bagian teknisi inilah yang nantinya memperbaiki terhadap Ticket yang di ajukan oleh user dari pihak KCP disuatu wilayah.

\subsection{Class Diagram}

Class Diagram adalah pandangan aplikasi yang bersifat statis. Class Diagram tidak hanya menggambarkan visualisasi, tetapi juga menggambarkan dan mendokumentasikan aspek yang berbeda dalam sistem, tetapi juga untuk kontruksi eksekusi kode dalam software aplikasi. Class diagram digunakan untuk mengelompokan hal-hal inti dari setiap proses yang ingin dilakukan. Semua proses dimasukkan ke dalam tiap-tiap class dan saling dihubungkan pada class-class lainnya yang saling berhubungan. Berikut ini adalah Class Diagram Sistem Informasi E-ticketing berbasis website

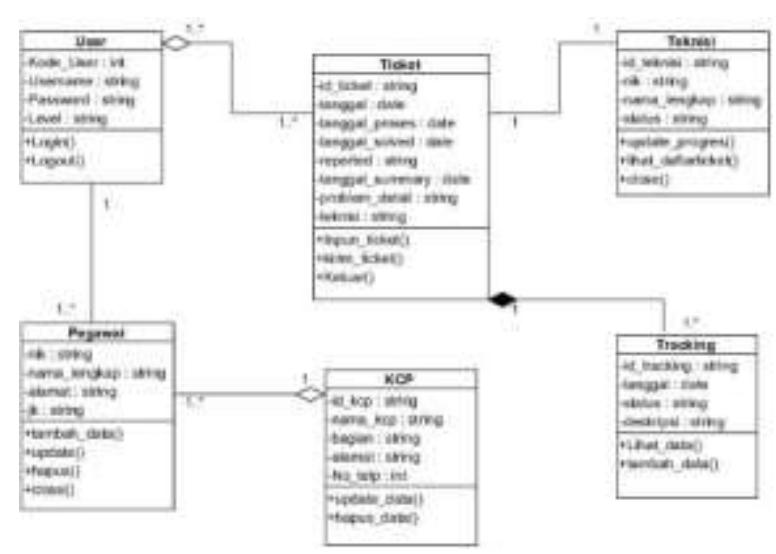

Gambar 2 Class diagram Sistem Informasi Eticketing berbasis website

Pada gambar class diagram diatas terdapat enam buah class, dimana setiap class tersebut saling terintegrasi satu sama lain. Class-class tersebut diantaranya ada class user, Class Ticket, class teknisi, class karyawan, class $\mathrm{KCP}$ dan class tracking. Class user merupakan class yang paling utama pada class diagram diatas, dikarenakan class tersebut merupakan class yang paling central untuk mengintegrasikan antara class-class yang lainnya.

\subsection{Entity relationship Digaram (ERD)}

ERD merupakan notasi grafis dalam pemodelan data konseptual yang digunakan untuk memodelkan struktur data dan hubungan antar data. Dengan ERD kita dapat menguji model dengan mengabaikan proses yang harus dilakukan. Dan dengan ERD juga bisa menjawab pertanyaan seperti : data apa yang kita perlukan ? 
bagaimana data yang satu berhubungan dengan data yang lain ? dan kenapa ERD diperlukan dalam menggambarkan sebuah sistem. Karena dalam ERD nantinya menggunakan sejumlah notasi dan symbol untuk menggambarkan struktur dan hubungan antar data, jadi setiap data yang saling berelasi akan kelihatan yang nantinya bisa dijadikan acuan sebagai perancangan dalam bentuk tabel dalam database.

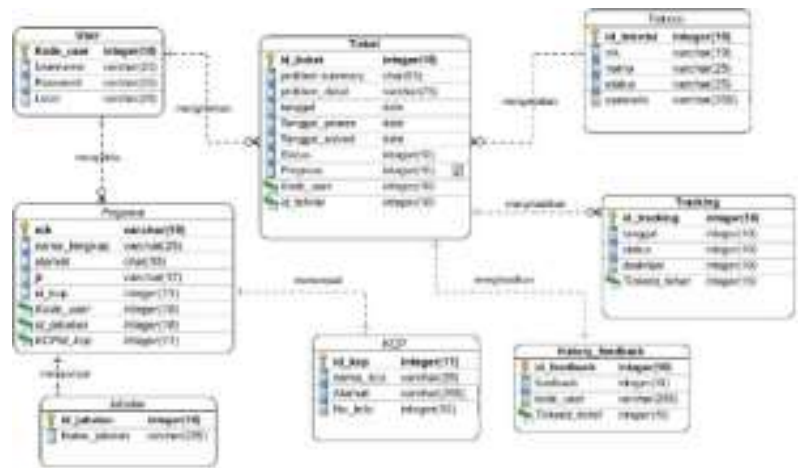

Gambar 3 Entity Relationship Diagram E-ticketing berbasis website

Pada gambar Entity Relationship Diagram ada delapan buah entitas, dimana kedelapan entitas tersebut adalah ada entitas user, entitas Ticket, entitas informasi, entitas teknisi, entitas karyawan, entitas KCP,entitas history_feedback dan entitas tracking. Setiap entitas tersebut mempunyai antributnya masing-masing, dimana setiap atribut yang berada dalam sebuah entitas merupakan ciri atau karakteristik dari sebuah entitas yang membedakan antara entitas yang satu dengan entitas yang lainnya.

\section{Perancangan Antarmuka \\ 6.1 Perancangan Antarmuka}

a. Perancangan Antarmuka Form Login

Form login berfungsi sebagai masukan untuk pengguna ketika akan mengakses halaman utama masing-masing, sehingga sistem akan menampilkan halaman utama sesuai dengan hak akses nya masingmasing.

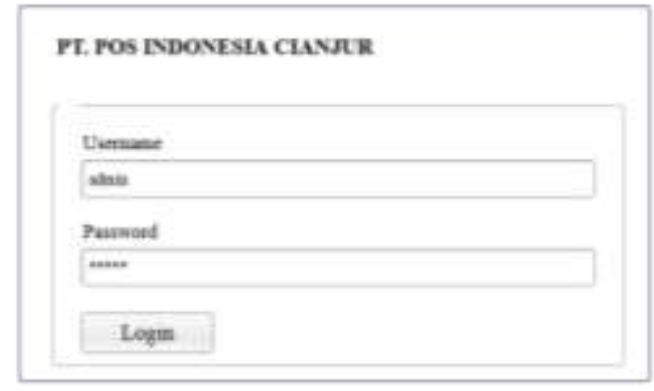

Gambar 4 Perancangan Antarmuka Halaman Login

b. Perancangan Antarmuka Halaman utama Admin

Halaman ini nantinya berfungsi untuk mengelola data ticket/Ticket dari user disetiap KCP, dan juga digunakan oleh admin untuk mengirimkan laporan ticket/Ticket dari user di setiap KCP. Berikut ini merupakan rancangan antarmuka untuk halaman utama admin.

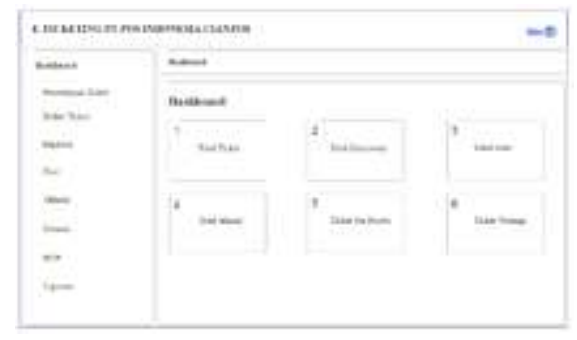

Gambar 5 Perancangan Antarmuka Halaman Utama Admin

\section{c. Perancangan Halaman Utama Teknisi}

Halaman utama ini hanya bisa diakses oleh bagian teknisi, halaman ini berfungsi sebagai halaman untuk menerima Ticket/ticket dari admin.

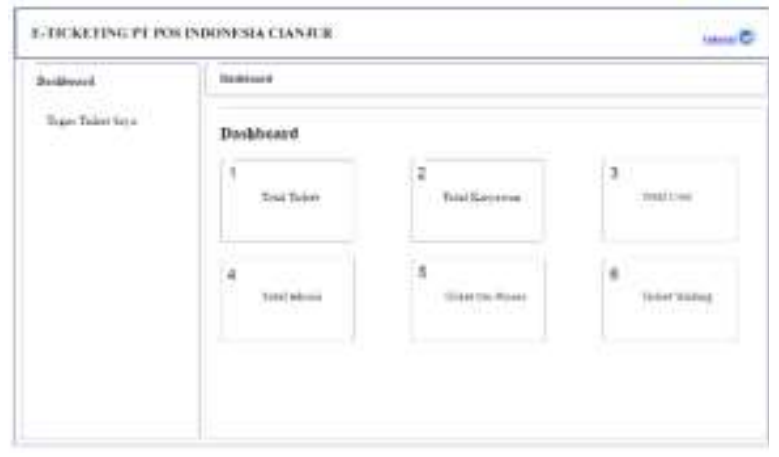

Gambar 6 Perancangan Antarmuka Halaman Utama Teknisi

d. Perancangan Antarmuka Halaman Utama User

Halaman ini nantinya digunakan oleh user yang ada disetiap KCP, sehingga nantinya user akan mengirimkan laporan atau ticket kepada admin.

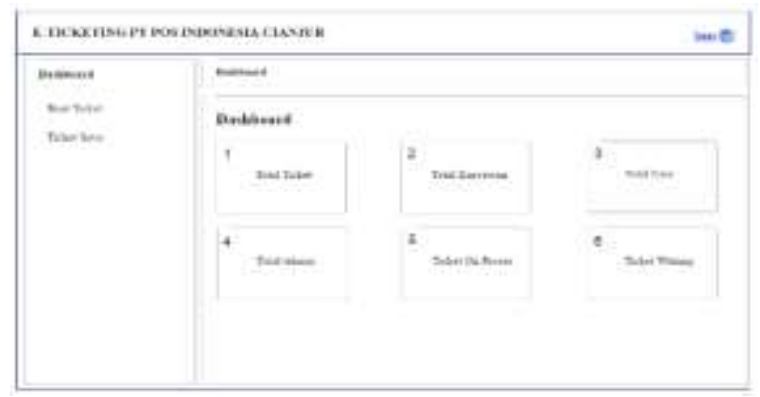

Gambar 7 Perancangan Antarmuka Halaman Utama User

\section{e. Perancangan Antarmuka Daftar Ticket/Ticket}

Halaman ini berfungsi untuk menampilkan daftar Ticket.ticket dari user disetiap KCP dan dari berbagai wilayah. 


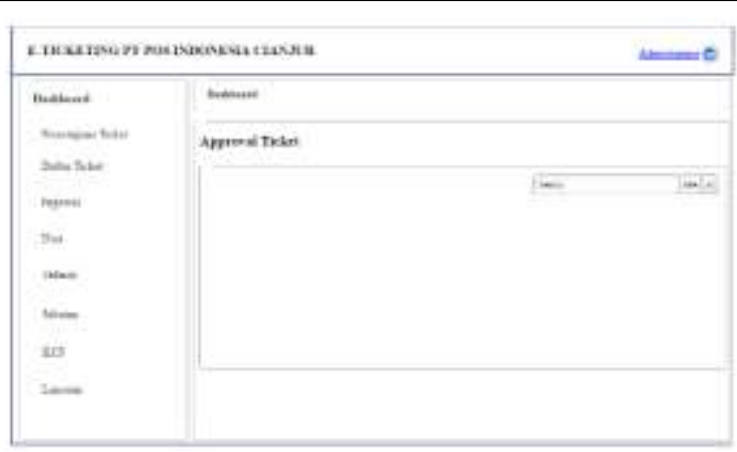

Gambar 8 Perancangan Antarmuka Daftar Ticket/Ticket

f.Perancangan Antarmuka Histori

Halaman ini juga berfungsi untuk menampilkan histori mengenai ticket/Ticket user di setiap KCP.

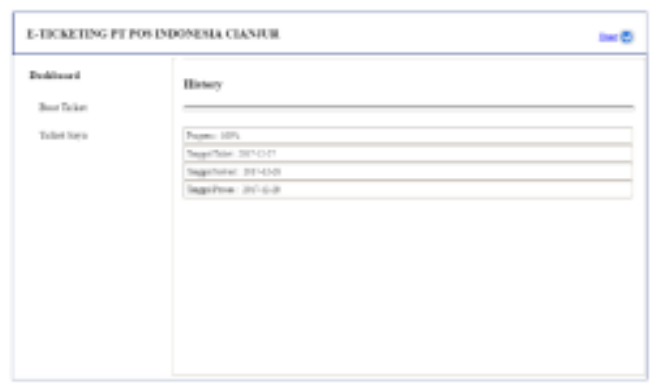

Gambar 9 Perancangan Antarmuka Histori

\section{g.Perancangan Antarmuka Ticket Saya}

Halaman ini berfungsi untuk menampilkan data ticket yang dikirimkan kepada admin, sehingga user bisa melihat status dari laporan yang dikirim.

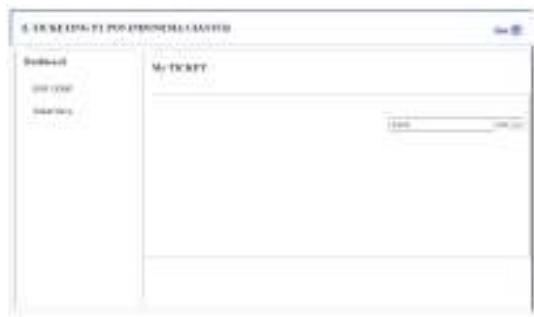

Gambar 10 Perancangan Antarmuka Tciket Saya

h.Perancangan Antarmuka Tugas Ticket

Halaman ini digunakan oleh teknisi untuk melihat daftar ticket/Ticket yang dikirimkan admin.

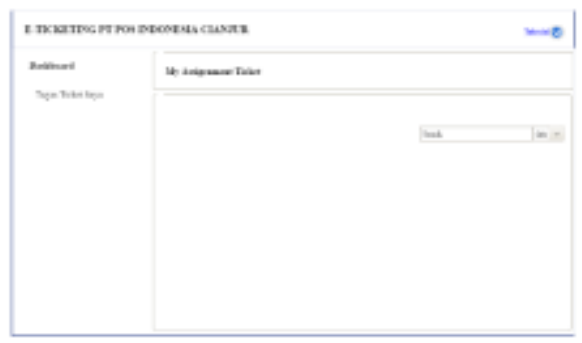

Gambar 11 Perancangan Antarmuka Tugas Ticket
i.Perancangan Antarmuka Buat Ticket/Ticket

Halaman ini digunakan oleh user untuk menginputkan data Ticket/ticket yang nantinya akan dikirimkan kepada admin.

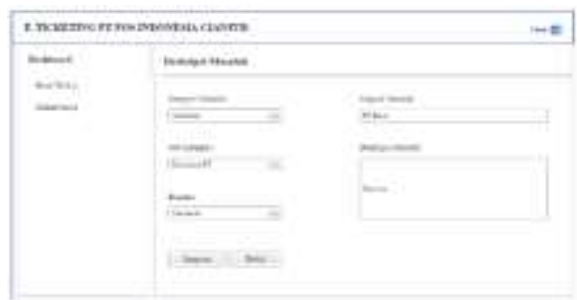

Gambar 12 Perancangan Antarmuka Buat Ticket

\section{Pengujian}

a. Pengujian Antarmuka Halaman utama Admin

Halaman ini nantinya berfungsi untuk mengelola data ticket/Ticket dari user disetiap KCP, dan juga digunakan oleh admin untuk mengirimkan laporan ticket/Ticket dari user di setiap KCP. Berikut ini merupakan rancangan antarmuka untuk halaman utama admin.

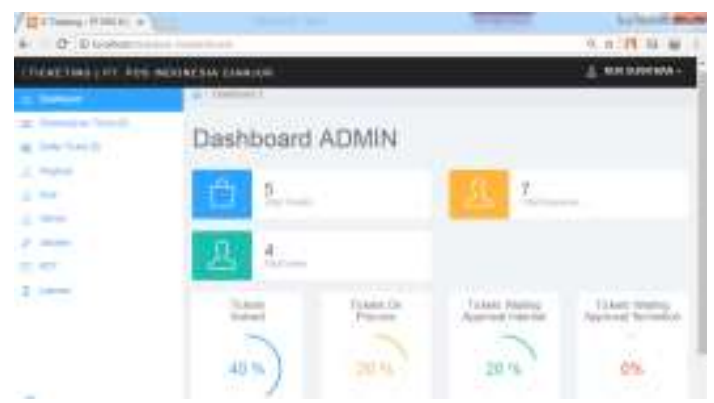

Gambar 13 Implementasi Antarmuka Halaman Utama admin

\section{b. Pengujian Halaman Utama Teknisi}

Halaman utama ini hanya bisa diakses oleh bagian teknisi, halaman ini berfungsi sebagai halaman untuk menerima Ticket/ticket dari admin.

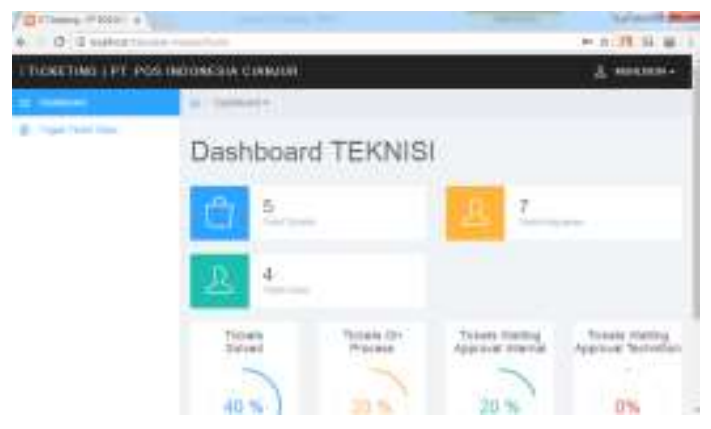

Gambar 14 Implementasi Antarmuka Halaman Utama Teknisi

c. Pengujian Antarmuka Halaman Utama User

Halaman ini nantinya digunakan oleh user yang ada disetiap KCP, sehingga nantinya user akan mengirimkan laporan atau ticket kepada admin. 


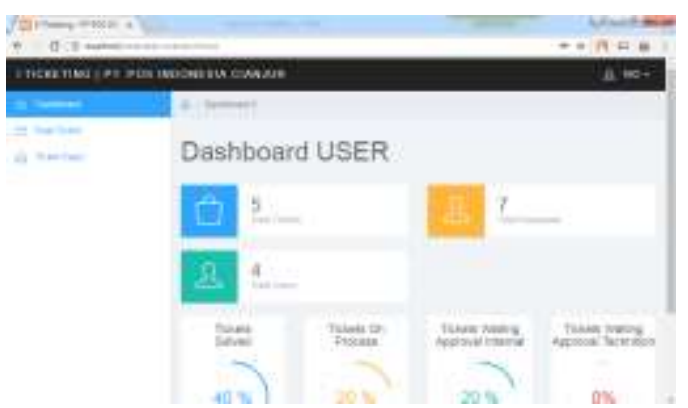

Gambar 15 Implementasi Antarmuka Halaman Utama User

\section{Kesimpulan}

Dari hasil analisis dan perancangan selama mengerjakan penelitian ini, maka kesimpulan yang dapat diambil adalah :

a. Sistem informasi e-ticketing merupakan sistem yang dibuat untuk menangani ticket atau Ticket dari user disetiap KCP dengan cepat, tepat, dan akurat.

b. Dengan adanya sistem informasi e-ticketing ini, diharapkan dapat mempermudah user dalam membuat laporan error atau kerusakan hardaware disetiap KCP terhadap admin.

c. Daftar ticket merupakan halaman yang menampilkan banyaknya ticket/Ticket disetiap KCP, sehingga dengan adanya fitur seperti ini admin dapat dengan mudah melakukan persetujuan terhadap ticket yang dikirimkan oleh user.

d. Dengan adanya sistem informasi e-ticketing ini, ketiga pengguna yaitu admin, user, dan teknisi dapat saling berelasi atau terintegrasi satu sama lainya, sehingga dapat menyelesaikan ketika ada ticket/Ticket yang dikirimkan oleh user di setiap KCP di berbagai wilayah.

\section{Saran}

Berdasarkan hasil dari kesimpulan yang didapat, maka penulis menyarankan agar sistem informasi e-ticketing ini dapat dipergunakan dengan baik, sehingga nantinya dapat membantu staff - staff yang ada di kantor Pos Indonesia dapat mengatasi permasalahan-permasalah yang sering kali terjadi disetiap KCP Pos Indonesia dengan cepat, tepat, dan akurat.

\section{Daftar Pustaka}

[1]. Amsyah, Zulkifli, 2003. Manajemen Sistem Informasi, PT.Gramedia Pustaka Utama, Jakarta.

[2]. Edisi 10, Terjemahan oleh Ali Akbar Yulianto dan Afia R. Fitriati, Salemba Empat, Jakarta.

[3]. Jogiyanto HM, 2005, Analisis \& Desain Sistem Informasi. Andi Offset, Yogyakarta

[4]. Kristanto, Andi. 2008. Perancangan Sistem Informasi dan Apilkasinya. Gava Media. Yogyakarta.

[5]. Laudon, Kenneth C. dan Jane P. Laudon. 2005. Sistem Informasi Manajemen: Mengelola Perusahaan Digital, Edisi kedelapan. Yogyakarta: Andi.

[6]. McLeod, Raymond, Jr \& schell, George P, 2008, Sistem Informasi Manajemen,
[7]. Sommerville, Ian. 2012. Software Engineering (Rekayasa Perangkat Lunak). Erlangga, Jakarta.

[8]. Santoso, 2009. Interaksi Manusia dan Komputer Edisi 2, Andi, Yogyakarta.

[9]. Syakur, Ahmad Syafi'i. 2009. Intermediate Accounting, AV Publisher, Jakarta. 